\title{
Patients' Question-Asking Behavior During Primary Care Visits: A Report From the AAFP National Research Network
}

\author{
James M. Galliber, $P b D^{1,2,3}$ \\ Douglas M. Post, $\mathrm{PbD}^{4}$ \\ Barry D. Weiss, $M D^{5}$ \\ L. Miriam Dickinson, $P b D^{1,3}$ \\ Brian K. Manning, MPH ${ }^{1}$ \\ Elizabetb W. Staton, MSTC ${ }^{1,3}$ \\ Judith Belle Brown, $P b D^{6}$ \\ Jobn M. Hickner, MD, MS \\ Aaron J. Bonbam, MS \\ Bridget L. Ryan, $P b D^{6}$ \\ Wilson D. Pace, $M^{1,3}$
}

'American Academy of Family Physicians National Research Network, Leawood, Kansas

${ }^{2}$ Department of Sociology, University of Missouri-Kansas City, Kansas City, Missouri

${ }^{3}$ Department of Family Medicine, University of Colorado Health Sciences Center at Denver, Denver, Colorado

${ }^{4}$ Department of Family Medicine, Ohio State University, Columbus, Ohio

${ }^{5}$ University of Arizona, Department of Family and Community Medicine, Tucson, Arizona

${ }^{6}$ Department of Family Medicine, University of Western Ontario, London, Ontario, Canada

${ }^{7}$ Department of Family Medicine, Cleveland Clinic, Cleveland, Ohio

${ }^{8}$ Department of Informatic Medicine and Personalized Health, University of Missouri-Kansas City, Kansas City, Missouri

Conflicts of interest: none reported

\section{CORRESPONDING AUTHOR}

James M. Galliher, PhD

AAFP National Research Network

11400 Tomahawk Creek Pkwy

Leawood, KS 66208

jgallihe@aafp.org

\begin{abstract}
PURPOSE The Ask Me 3 (AM3) health communication program encourages patients to ask specific questions during office visits with the intention of improving understanding of their health conditions and adherence to treatment recommendations. This study evaluated whether implementing AM3 improves patients' question-asking behavior and increases adherence to prescription medications and lifestyle recommendations.
\end{abstract}

METHODS This randomized trial involved 20 practices from the American Academy of Family Physicians National Research Network that were assigned to an AM3 intervention group or a control group. Forty-one physicians in the practices were each asked to enroll at least 20 patients. The patients' visits were audio recorded, and recordings were reviewed to determine whether patients asked questions and which questions they asked. Patients were interviewed 1 to 3 weeks after the visit to assess their recall of physicians' recommendations, rates of prescription filling and taking, and attempts at complying with lifestyle recommendations.

RESULTS The study enrolled 834 eligible patients in 20 practices. There were no significant difference between the AM3 and control patients in the rate of asking questions, but this rate was high (92\%) in both groups. There also were no differences in rates of either filling or taking prescriptions, although rates of these outcomes were fairly high, too. Control patients were more likely to recall that their physician recommended a lifestyle change, however ( $68 \%$ vs $59 \%, P=.04$ ).

CONCLUSIONS In a patient population in which asking questions already occurs at a high rate and levels of adherence are fairly high, we found no evidence that the AM3 intervention results in patients asking specific questions or more questions in general, or in better adherence to prescription medications or lifestyle recommendations.

Ann Fam Med 2010;8:151-159. doi:10.1370/afm.1055

\section{INTRODUCTION}

$\mathrm{N}$ umerous studies document the need to improve physician-patient communication..$^{1-4}$ Patients report that physicians are not sufficiently attentive to their concerns, and patients often do not understand what they are told. ${ }^{5}$ When interviewed immediately after office visits, patients recall only one-half or less of important information given to them. ${ }^{2}$

Limited health literacy can further complicate communication between physicians and patients. ${ }^{4}$ Patients with limited capacity to "obtain, process, and understand basic health information and services needed to make appropriate health decisions ${ }^{16}$ have trouble understanding common medical terms and written health-related materials. ${ }^{7-12}$

Research suggests that better physician-patient communication improves patient outcomes. ${ }^{13-18}$ Yet, some physicians view better communication as time-consuming and impractical during office visits averaging only 17 minutes. ${ }^{19}$ 
Ask Me 3 (AM3) is a simple approach designed to facilitate communication between health care professionals and patients. AM3 was developed by the Partnership for Clear Health Communication (http://www. npsf.org/askme3/). The AM3 approach encourages patients to ask 3 questions at every visit with a clinician: (1) What is my main problem? (2) What do I need to do (about the problem)? and (3) Why is it important for me to do this? The AM3 program is based on the theoretical argument that patients' increased communication (via patient question-asking) and subsequent understanding (or increased health literacy) will lead to better adherence to treatment recommendations (eg, recommended medication and lifestyle changes).

This study compared patient-physician communication between primary care practices that implemented the AM3 program and control primary care practices that did not. We conducted a practical clinical trial, a design that examines interventions as they would occur in routine clinical practice, and that provides useful information regarding clinical effectiveness. ${ }^{20}$ Our research questions were as follows: (1) Does the AM3 intervention affect patients' question-asking behavior? (2) Does the AM3 intervention affect adherence to selected physicians' treatment recommendations? and (3) Is there a relationship between patient question-asking, in general, and these same adherence outcomes? Our prestudy hypotheses were that (1) patients in practices implementing AM3 would average more questions than patients in control practices; (2) patients in AM3 practices would show greater adherence to physicians' treatment recommendations; and (3) as patients ask more questions, they would show greater adherence to physicians' treatment recommendations.

\section{METHODS}

\section{Overview}

This practical clinical trial, known as the Improving Communication During Office Visits trial, involved 20 primary care practices from the American Academy of Family Physicians National Research Network (AAFP NRN). Practices were randomly assigned to an AM3 intervention group or to a control group in which AM3 was not introduced. The study was approved by the University of Missouri-Kansas City Social Science Institutional Review Board (IRB) and local IRBs of participating practices. Patient enrollment and data collection occurred between November 2004 and May 2005.

\section{Practices}

We randomly assigned 10 practices to the intervention group and 10 to the control group. The study sites were located in 18 states distributed across the United
States. The practices included 41 physicians: 23 in AM3 practices and 18 in control practices. Practices in both study groups ranged in size from 1 physician to 3 or more. Five practices ( 3 AM3) were urban, 6 practices (2 AM3) were suburban, and 9 practices (5 AM3) were rural. Most practices were physician owned; 8 (4 AM3) were residency programs.

\section{Patients}

Each practice recruited 20 to 25 patients per study physician based on sample size calculations described below. Each practice selected, a priori, a sampling strategy for patient enrollment: every second, third, fourth, or fifth patient who visited the office on a given day to see the study physician for any reason. Office study coordinators obtained informed consent from patients.

Eligible patients were aged 18 years or older and capable of giving informed written consent in either English or Spanish. Patients were excluded if pregnant, too ill to participate, or not capable of being contacted by telephone for a follow-up interview.

\section{AM3 Intervention Group}

We used several strategies simultaneously to introduce AM3 into the intervention practices. First, AM3 brochures were made available in waiting rooms, and AM3 posters were placed in waiting rooms and examination rooms. Second, front office staff members were trained to give AM3 pamphlets to patients at check-in. Third, when nurses and medical assistants escorted patients to examination rooms, they reminded patients to ask the physician the 3 questions. Patients also could write their questions in the provided pamphlets to address with their physician later.

Intervention practices were instructed to implement the intervention as described here in their practices for at least 1 week before enrolling patients. Physicians and staff from these practices attended a 1-day face-to-face training session (in Kansas City, Missouri) that covered both the AM3 program and the study protocol.

\section{Control Group}

Physicians and staff from the control group practices attended a separate training session in which data collection protocols were reviewed. They were not told about AM3 or specific details about health literacy. They were instead informed that we were conducting a study about physician-patient communication, and they were asked not to change their current communication behaviors with patients during the study. Control practices received the AM3 information after the study ended. 


\section{Data Collection}

Data were collected from patients and physicians, and from their interaction during the visit using 2 questionnaires, audio recordings, and a follow-up telephone interview (Table 1).

\section{Patient Postvisit Questionnaire}

Immediately after their office visit, patients in both groups completed a questionnaire. The questionnaire asked about demographics and health literacy. The literacy items were drawn from previously validated instruments ${ }^{21}$ and modified to decrease the reading demand and to place questions in a primary care rather than hospital-based context.

\section{Physician Postvisit Questionnaire}

Physicians in both groups completed a questionnaire immediately after the patient visit. The questionnaire asked (1) about the physician's perceptions of her/his communication with the patient, (2) about the nature of the patient's problems, (3) whether medications were prescribed, and (4) whether lifestyle changes were recommended.

\section{Recordings of Physician-Patient Visits}

In both sets of practices, staff placed an audio recorder in the examination room, and the entire office visit of consenting patients was recorded. The recordings were mailed to the AAFP NRN for review and coding. Information abstracted for coding included (1) number of times each AM3 question was asked, (2) total number of AM3 questions asked, (3) total number of questions of any type asked, (4) whether a medication was prescribed, and (5) whether a lifestyle recommendation was made. Coders worked together during the first few days of coding and subsequently once per week using the same audio recordings to check each others' coding, interpretations, and assumptions. Where differences occurred, consensus was reached on interpretation and coding decisions.

We assessed reliability of these measures by having the 2 (of the project's 5) research associates who had coded the majority of recordings randomly select $75(10 \%)$ of the recordings and independently code the same information, and then evaluating the concordance between the 2 coders. The coders' agreement was 97\% ("Was Ask Me 3 question 1 asked?"), 68\% ("Was Ask Me 3 question 2 asked?"), and 93\% ("Was Ask Me 3 question 3 asked?"), with a mean agreement across the 3 items of $86 \%$. These items' $\kappa$ values were $0.653,0.138$, and 0.269 , respectively.

\section{Patient Postvisit Telephone Interview}

Patients were telephoned for follow-up interviews if their physician indicated that a new or refill medication
Table 1. Data Collection: Sources and Timing

\begin{tabular}{llc}
\hline Source & $\begin{array}{c}\text { Timing of } \\
\text { Collection }\end{array}$ & $\begin{array}{c}\text { No. (\%) of } \\
\text { Enrolled Patients } \\
\text { With Usable Data } \\
\text { (n = 834) }\end{array}$ \\
\hline $\begin{array}{l}\text { Patient postvisit } \\
\text { questionnaires } \\
\begin{array}{l}\text { Physician postvisit } \\
\text { questionnaires }\end{array}\end{array}$ & $\begin{array}{c}\text { Immediately } \\
\text { after visit } \\
\text { Immediately } \\
\text { after visit }\end{array}$ & $829(99)$ \\
$\begin{array}{l}\text { Audio recordings } \\
\text { Patient follow-up tele- } \\
\text { phone interviews }\end{array}$ & $\begin{array}{l}\text { About 2 weeks } \\
\text { after visit }\end{array}$ & $729(99)$ \\
$\begin{array}{l}\text { a Of 524 patients eligible for follow-up. Patients were eligible for a follow-up } \\
\text { telephone interview if their study physician stated in the postvisit question- } \\
\text { naire that a prescription (new, refill, both) had been written at the office visit. }\end{array}$ \\
\hline
\end{tabular}

Table 2. Selected Questions Asked of Patients During the Follow-up Telephone Interview

1. Did [name of study physician] write/give you any new prescriptions at that visit?a

2. Have you had these new prescriptions filled at a pharmacy?

3. Did [name of study physician] write you any refill prescriptions for medicine you were taking before this doctor's visit?a

4. Have you had these prescriptions filled at a pharmacy? ${ }^{a}$

5. How many of the medications (new and old) that were prescribed to you at the visit are you taking? ${ }^{b}$

a Response options were Yes, No, and Don't remember

${ }^{b}$ Response options were All of them, Some of them, and None of them.

had been prescribed at the visit. The mean number of days between the index visit and follow-up was 14.2 $(\mathrm{SD}=10.1)$ and $14.1(\mathrm{SD}=12.3)$ for the intervention and control patients, respectively. Across all eligible patients, $84 \%$ were interviewed within 3 weeks. The interviewers asked about patients' adherence to recommendations made during the visit (Table 2).

\section{Data Analysis}

Statistical analyses were conducted using SPSS, version 11.5.1 (SPSS for Windows, SPSS Inc, Chicago, Illinois) and SAS 9.1 (SAS Institute Inc, Cary, North Carolina). We computed frequency distributions and descriptive statistics for survey questions and abstracted items from the audio recordings. We used $\chi^{2}$ tests and $t$ tests for categorical and continuous dependent variables, respectively, when assessing the bivariate relationships.

Multivariate analyses were used to address the primary research questions using general linear mixed models (SAS Proc Mixed) for continuous (or semicontinuous) outcomes or generalized linear mixed models with logit link (SAS Proc Glimmix) for dichotomous outcomes, adjusting for patients clustered within physicians. ${ }^{22,23}$ Although physicians were clustered within practices, in most cases, there were too few physicians per practice to model both physician- and practice- 
level random effects. Patient sex, age category, race/ ethnicity, marital status, education, health literacy, and number of years with study physician were included as covariates in every model with group (intervention vs control) included as a fixed effect.

We calculated that a minimum sample size of 400 patients in each group would provide $80 \%$ power to detect a difference $(\alpha=.05)$ of $25 \%$ between the intervention and control patients in asking 1 or more AM3 questions. We assumed an intraclass correlation coefficient (patients within physicians) of 0.10 and estimated that about $50 \%$ of the intervention patients would ask some variant of these questions, compared with $25 \%$ of the control patients.

\section{RESULTS}

\section{Participation Rates and Usable Data}

Overall, 1,088 patients were invited and 834 (77\%) consented to participate in the study -445 (76\%) in intervention practices and $389(78 \%)$ in control practices (Figure 1). Data from 5 patients were unusable (because the patients were underage or their signed informed consent form was missing), leaving 829 patients. The intervention physicians enrolled an average of 19.3 patients $(\mathrm{SD}=7.4$, median $=23)$, compared with 21.6 patients $(\mathrm{SD}=3.7$, median $=21)$ for the control physicians. In all, 763 (92\%) of the audio recordings were usable. Reasons for unusable audio recordings included the recorder was not turned on, the

\section{Figure 1. Recruitment of practices and patients into the trial assessing the effects of the Ask Me 3 patient intervention.}

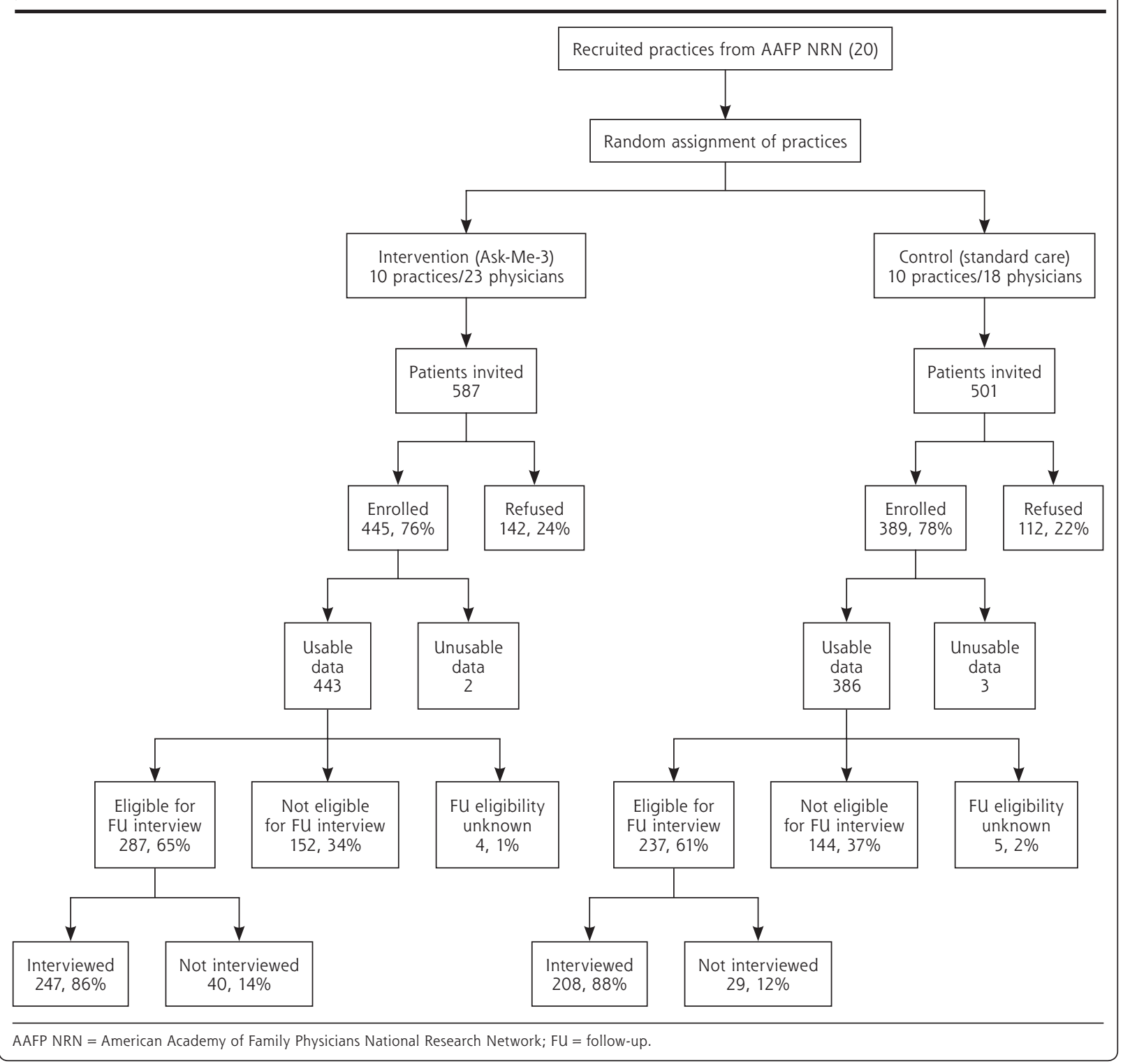




\begin{tabular}{|c|c|c|c|}
\hline Characteristic & $\begin{array}{c}\text { Intervention } \\
\text { Patients } \\
\% \text { or Mean }\end{array}$ & $\begin{array}{c}\text { Control } \\
\text { Patients } \\
\% \text { or Mean }\end{array}$ & $P$ Value \\
\hline $\operatorname{Sex}(n)$ & (443) & (386) & $.06^{\mathrm{a}}$ \\
\hline Male & 68 & 62 & \\
\hline Female & 32 & 38 & \\
\hline Age category (n) & $(435)$ & (382) & $.09^{\mathrm{a}}$ \\
\hline $18-30 y$ & 14 & 10 & \\
\hline $31-40$ y & 15 & 12 & \\
\hline $41-50 y$ & 19 & 25 & \\
\hline $51-60$ y & 19 & 24 & \\
\hline $61-70 y$ & 19 & 17 & \\
\hline $71-80$ y & 14 & 12 & \\
\hline Racial identification (n) & (431) & (378) & $.60^{\mathrm{a}}$ \\
\hline White & 85 & 83 & \\
\hline Black & 10 & 12 & \\
\hline Other $/ \geq 2$ responses & 4 & 5 & \\
\hline Ethnic identification (n) & (431) & (378) & $.002^{\mathrm{a}}$ \\
\hline Hispanic & 10 & 4 & \\
\hline Not Hispanic & 90 & 96 & \\
\hline Current marital status (n) & (434) & (383) & $.048^{\mathrm{a}}$ \\
\hline Married & 64 & 54 & \\
\hline Living together & 4 & 6 & \\
\hline Separated & 4 & 3 & \\
\hline Divorced & 10 & 14 & \\
\hline Widowed & 9 & 12 & \\
\hline Never married & 10 & 12 & \\
\hline Employed full-time (n) & (434) & (383) & $.21^{\mathrm{a}}$ \\
\hline Yes & 44 & 40 & \\
\hline No & 56 & 60 & \\
\hline Employed part-time (n) & (443) & (386) & $.63^{\mathrm{a}}$ \\
\hline Yes & 13 & 14 & \\
\hline No & 87 & 86 & \\
\hline Retired (n) & (443) & (386) & $.05^{\mathrm{a}}$ \\
\hline Yes & 26 & 20 & \\
\hline No & 74 & 80 & \\
\hline Educational attainment (n) & (432) & (384) & $.02^{\mathrm{a}}$ \\
\hline$<$ High school & 11 & 16 & \\
\hline High school graduate & 33 & 28 & \\
\hline Some college & 30 & 27 & \\
\hline College graduate & 19 & 16 & \\
\hline Postgraduate study & 8 & 13 & \\
\hline $\begin{array}{l}\text { Years as patient of study } \\
\text { physician (n) }\end{array}$ & $3.07(281)$ & $3.37(221)$ & $.07^{\mathrm{b}}$ \\
\hline Source of insurance (n) & (433) & (380) & $.07^{\mathrm{a}}$ \\
\hline Private & 50 & 47 & \\
\hline Medicare & 31 & 27 & \\
\hline Medicaid & 6 & 8 & \\
\hline Self-pay & 8 & 13 & \\
\hline Other & 5 & 6 & \\
\hline
\end{tabular}

recording was not audible, and the recorder stopped before the visit ended.

\section{Participating vs Nonparticipating Patients}

In total, 193 (76\%) of the 254 patients who declined participation provided their demographic information. Younger patients were more likely to have participated than older patients (mean age, 51.6 vs 57.6 years; $P<.001)$. Men and women did not differ significantly in their participation, and racial identification did not differ between the participants and nonparticipants (data not shown).

\section{Patients' Demographics and Health Literacy}

Intervention and control patients did not differ $(P>.05)$ with respect to sex, age, racial identification, employment, retirement status, source of insurance, or years as a patient of the study physician (Table 3 ). The 2 groups did differ in terms of ethnic identification, marital status, and educational attainment. Specifically, intervention patients were more likely to be Hispanic $(P=.002)$ and married $(P=.048)$, and less likely to report both lack of high school graduation (11\% vs $16 \%$ ) and lack of postcollege study ( $8 \%$ vs $13 \%$ ), but also more likely to report high school graduation, some college education, and college graduation (combined $82 \%$ vs $71 \%, P=.02$ ).

The patients' responses to the 3 questions about health literacy revealed differences between the groups for the question, "How easy or hard is it to fill out medical forms by yourself?" (Table 4). Intervention patients were more likely to respond either "extremely easy" or "very easy" compared with control patients (70\% vs $62 \%, P=.001)$.

\section{Rates of Question-Asking}

Hypothesis 1 stated that intervention patients would ask more questions on average than control patients. There was no statistically significant difference between the groups in asking questions (Table 5) as measured by (1) the percentage of patients asking 1 or more AM3 questions $(26 \%$ vs $30 \%, P=.16)$; (2) the percentage of patients asking at least 1 question of any type (92\% vs $92 \%, P=.87) ;$ (3) the mean number of AM3 questions asked (0.47 vs $0.52, P=.56)$; and (4) the mean number of any questions asked, including AM3 ques- 
tions (6.94 vs $6.37, P=.23)$ and excluding AM3 questions ( 6.46 vs $5.86, P=.18)$. When study patients who ranked the lowest on the second health literacy question (ease of filling out medical forms) were compared with patients with higher rankings, their respective means were 5.4 vs 6.7 for all questions asked $(P=.22)$ and 5.1 vs 6.2 for all non-AM3 questions asked $(P=.24)$.

Multivariate analyses yielded similar results. Intervention patients were no more likely than control patients to ask any of the $3 \mathrm{AM} 3$ questions $\left(\mathrm{F}_{1,39}=1.18\right.$, $P=.34)$, even after adjusting for patient age, sex, race/ ethnicity, marital status, education, health literacy, and number of years with the primary care physician. Multivariate analyses also yielded similar results for num-

\begin{tabular}{|c|c|c|c|}
\hline Health Literacy Question & $\begin{array}{l}\text { Intervention } \\
\text { Patients, \% }\end{array}$ & $\begin{array}{c}\text { Control } \\
\text { Patients, \% }\end{array}$ & $P$ Value \\
\hline $\begin{array}{l}\text { How often does someone help you read } \\
\text { things your doctor gives you? (n) }\end{array}$ & $(436)$ & (373) & $.15^{\mathrm{a}}$ \\
\hline Always/often & 11 & 15 & \\
\hline Sometimes & 28 & 25 & \\
\hline Never & 62 & 60 & \\
\hline $\begin{array}{l}\text { How easy or hard is it to fill out medical } \\
\text { forms by yourself? ( } n \text { ) }\end{array}$ & (435) & (370) & $.001^{\mathrm{a}}$ \\
\hline Extremely/very hard & 3 & 8 & \\
\hline Somewhat hard/easy & 27 & 29 & \\
\hline Extremely/very easy & 70 & 62 & \\
\hline $\begin{array}{l}\text { How often is it hard to understand writ- } \\
\text { ten information about your medical } \\
\text { problems? (n) }\end{array}$ & $(436)$ & (372) & $.65^{\mathrm{a}}$ \\
\hline Always/often & 7 & 9 & \\
\hline Sometimes & 54 & 55 & \\
\hline Never & 39 & 36 & \\
\hline
\end{tabular}

ber of AM3 questions asked $\left(F_{1,39}=0.11, P=.83\right)$, and number of all questions asked including AM3 $\left(\mathrm{F}_{1,39}=\right.$ $0.001, P=.82)$ and excluding AM3 $\left(F_{1,39}=0.01, P=.80\right)$.

\section{Question-Asking and Adherence}

Hypothesis 2 stated that intervention patients would show greater adherence to physicians' treatment recommendations. The adherence outcomes in the intervention group were no better than those in the control group (Table 6). The only comparison showing a significant difference indicated that control patients were more likely than intervention patients to accurately recall their physician's recommending lifestyle change(s) during the visit (68\% vs $59 \%, P=.04)$. These 2 patient groups did not differ with respect to attempting recommended lifestyle changes, however $(92 \%$ vs 93\%, $P=.90)$.

Hypothesis 3 stated that as patient question-asking behavior increases, patients would show greater adherence to physicians' treatment recommendations. There were no significant differences in these outcomes based on whether patients asked the AM3 questions or any questions in general (data not shown). Adjusting for potential confounders in the multivariate analyses did not change these results (all $P>$.05).

\section{DISCUSSION}

With data gathered from a national practice-based research network, we

Table 5. Question-Asking Behavior by Patients in Intervention Practices ( $n=415$ Patients) and Control Practices ( $n=352$ Patients) as Determined From Audio Recordings

\begin{tabular}{|c|c|c|c|c|c|c|}
\hline \multirow[b]{2}{*}{ Measure } & \multicolumn{3}{|c|}{ Unadjusted } & \multicolumn{3}{|c|}{ Adjusted $^{a, b}$} \\
\hline & $\begin{array}{l}\text { Intervention } \\
\text { Patients } \\
\% \text { or Mean }\end{array}$ & $\begin{array}{c}\text { Control } \\
\text { Patients } \\
\% \text { or Mean }\end{array}$ & $P$ Value & $\begin{array}{l}\text { Intervention } \\
\text { Patients } \\
\% \text { or Mean }\end{array}$ & $\begin{array}{c}\text { Control } \\
\text { Patients } \\
\% \text { or Mean }\end{array}$ & $P$ Value \\
\hline $\begin{array}{l}\text { Did patient ask any AM3 questions? } \\
\text { (\% Yes) }\end{array}$ & 26 & 30 & $.16^{c}$ & 26 & 31 & .34 \\
\hline $\begin{array}{l}\text { Did patient ask any questions of any } \\
\text { type? (\% Yes) }\end{array}$ & 92 & 92 & $.87^{c}$ & 92 & 91 & .84 \\
\hline Number of AM3 questions & 0.47 & 0.52 & $.56^{\mathrm{d}}$ & 0.50 & 0.53 & .83 \\
\hline Number of questions including AM3 & 6.94 & 6.37 & $.23^{\mathrm{d}}$ & 6.75 & 6.55 & .82 \\
\hline Number of questions excluding AM3 & 6.46 & 5.86 & $.18^{d}$ & 6.23 & 6.03 & .80 \\
\hline \multicolumn{7}{|c|}{$\begin{array}{l}\text { AM3 = Ask Me } 3 . \\
\text { a F statistic from generalized linear mixed models (for categorical data) or general linear mixed models (for continuous data). } \\
\text { b Adjusted for clustering and the following covariates: age, sex, race/ethnicity (non-Hispanic white vs other/missing), education, years with physician. } \\
\text { ' } \chi^{2} \text { test. } \\
\text { d Student } t \text { test for independent samples. }\end{array}$} \\
\hline
\end{tabular}




\begin{tabular}{|c|c|c|c|c|c|c|}
\hline \multirow[b]{2}{*}{ Outcome } & \multicolumn{3}{|c|}{ Unadjusted } & \multicolumn{3}{|c|}{ Adjusted $^{a, b}$} \\
\hline & $\begin{array}{l}\text { Intervention } \\
\text { Patients } \\
\% \text { or Mean }\end{array}$ & $\begin{array}{c}\text { Control } \\
\text { Patients } \\
\% \text { or Mean }\end{array}$ & $\begin{array}{l}\chi^{2} \text { Test } \\
P \text { Value }\end{array}$ & $\begin{array}{l}\text { Intervention } \\
\text { Patients } \\
\% \text { or Mean }\end{array}$ & $\begin{array}{c}\text { Control } \\
\text { Patients } \\
\% \text { or Mean }\end{array}$ & $P$ Value \\
\hline Accurately recalled any prescription (n) & (247) & (206) & .45 & & & .41 \\
\hline Yes & 92 & 90 & & 92.9 & 90.8 & \\
\hline No & 8 & 10 & & & & \\
\hline Accurately recalled new prescription (n) & $(182)$ & (127) & .40 & & & .54 \\
\hline Yes & 74 & 69 & & 74.2 & 70.4 & \\
\hline No & 26 & 31 & & & & \\
\hline Accurately recalled refill prescription (n) & $(101)$ & (123) & .67 & & & .68 \\
\hline Yes & 81 & 79 & & 81.0 & 78.2 & \\
\hline No & 19 & 21 & & & & \\
\hline Filled new prescriptionc $(n)$ & (143) & (104) & .75 & & & .82 \\
\hline Yes & 81 & 83 & & 81.1 & 82.4 & \\
\hline No & 19 & 17 & & & & \\
\hline Filled refill prescriptionc (n) & (113) & (123) & .99 & & & .71 \\
\hline Yes & 70 & 70 & & 68.6 & 71.0 & \\
\hline No & 30 & 30 & & & & \\
\hline Was taking $\geq 1$ prescription ${ }^{d}(n)$ & (205) & $(170)$ & .91 & & & .96 \\
\hline Yes & 90 & 91 & & 90.3 & 90.5 & \\
\hline No & 10 & 9 & & & & \\
\hline $\begin{array}{l}\text { Accurately recalled lifestyle recommen- } \\
\text { dations (n) }\end{array}$ & $(242)$ & (206) & .04 & & & .14 \\
\hline Yes & 59 & 68 & & 59.3 & 68.4 & \\
\hline No & 41 & 32 & & & & \\
\hline Attempted lifestyle change ${ }^{e}(n)$ & (95) & $(102)$ & .90 & & & .78 \\
\hline Yes & 93 & 92 & & 93.3 & 92.3 & \\
\hline No & 7 & 8 & & & & \\
\hline \multicolumn{7}{|c|}{$\begin{array}{l}\text { a F statistic from generalized linear mixed model. } \\
\text { b Adjusted for clustering and the following covariates: age, sex, race/ethnicity (non-Hispanic white vs other/missing), education, years with physician. } \\
\text { ' Patients' self-reports of filling prescription among those reporting having received a prescription at the visit. Some of these patients' physicians stated that they did } \\
\text { not write a prescription at the visit. }\end{array}$} \\
\hline
\end{tabular}

found no evidence that the AM3 intervention results in patients asking their physicians a greater number of questions or more specific questions. The intervention did not improve adherence to treatment as we defined it, a finding consistent with previous studies that used similar, simple communication interventions. ${ }^{24-26}$

In contrast, studies that use interventions that are more personalized (eg, requesting patients to list the questions they have before seeing the clinician) or intensive (eg, a 15-minute previsit training session with a communications specialist) tend to find significant effects on both question frequency and patients' adherence to treatment recommendations. ${ }^{24,27-30}$

One explanation for our findings, however, is not that the AM3 intervention lacks effect but rather that a ceiling effect prevented detection of differences between the 2 groups. With more than 9 of 10 patients in the control group already asking questions even without prompting, and the vast majority filling recommended prescriptions for medications $(70 \%$ for refills and $>80 \%$ for new medications), it would be difficult for any intervention to improve question asking or adherence. In addition, our sample may not be the appropriate target for an intervention such as AM3, as the health literacy levels and educational attainment of both patient groups were relatively high. It is possible that $\mathrm{AM} 3$ might be more effective among patients who have lower health literacy skills. Our study had relatively few low-literacy individuals, and we could not demonstrate an effect for this subgroup. Although not statistically significant, the data suggested that patients scoring lower on health literacy were more likely to ask fewer questions overall during their office visits. 
Another possibility is that physicians in the intervention group may have anticipated the specific AM3 questions. That is, rather than waiting for questions to be asked explicitly by patients, physicians may have "answered" these questions in advance. To examine this possibility we reviewed a random sample of 75 (17\%) of the intervention visits recordings and did not find any instances in which physicians preemptively "answered" the AM3 questions.

Regardless of the reason for our findings, they are nonetheless important to consider when selecting patient communication interventions to use in clinical settings. A more specific, personalized intervention, supported by more detailed training and supplemented by coaching, may have been more effective, but also more expensive, complicated, and labor intensive. ${ }^{17,24,27-33}$ Unfortunately, this type of intervention typically is not sustainable in practice once research funding has ceased.

Alternative methods of communication, other than a question-prompting intervention, are available and may improve patients' understanding of health information. These methods include technology-based approaches such as interactive video applications, audiotapes, electronic linkages to patient education, computerized reminders to both patients and physicians, and others. ${ }^{33,34}$ Additional research is warranted to define the effectiveness of such approaches in primary care.

\section{Limitations}

There are several limitations of this study, including the possible variation in how AM3 was implemented in practices. Even though the physicians and staff in the intervention practices participated in both centralized and telephone training, actual implementation of AM3 was the responsibility of 1 physician and 1 study coordinator per practice. Variability in how the intervention is delivered is common in effectiveness trials and mimics how AM3 would be used in clinical practice.

Self-report bias is other possible limitation. Data on patient prescription filling and taking were based on self-reports, not pharmacy records. The possibility of this bias is noteworthy because patients did not always recall visit content accurately_-substantial proportions did not remember being prescribed a new medication (25\%) or refill medication (23\%), even when physicians' postvisit questionnaires indicated that such prescribing had occurred. Similarly, a sizable proportion (37\%) did not accurately recall their physician's recommendations for lifestyle changes.

For both prescription ordering and lifestyle recommendations, however, we based recall accuracy on patient interview data and its agreement with the physician report. In at least some cases, physician reports of prescription ordering and behavioral recom- mendations - rather than patient reports - conceivably were the ones in error. We conducted follow-up interviews with 75 (25\%) of the noneligible patients, that is, patients whose study physicians reported that they had not ordered either a new or refill prescription at the visit. When these patients were queried, 22 (29\%) reported having received either a new or refill prescription at that visit. This finding suggests there were recall errors on the part of patients and physicians alike. Even so, there is no indication that such errors were more likely to affect 1 group compared with the other.

Another study limitation is the lack of baseline measurement on question-asking behavior among both control and intervention patients. This study gathered question-asking behavior and adherence information only after AM3 had been implemented in the intervention practices. A longitudinal design allowing for both baseline measurement and statistical controls for possible differences between intervention and control patients at baseline would have provided a more rigorous assessment of the AM3 intervention.

In addition, a Hawthorne effect may have influenced our findings. Patients in both the intervention and control groups were informed that this was a study on communication - a focus that was reinforced by the presence of a tape recorder in examination rooms. Patients may have changed how they typically communicated and asked more questions in this office visit. Blinding patients in the control group to the nature of the study, as was done in the Direct Observation of Primary Care (DOPC) study, may have helped to address this issue. ${ }^{34}$

We found that the AM3 intervention did not increase the frequency of patient question-asking either for the AM3 questions specifically or for questions generally. The AM3 intervention also did not improve patient adherence to treatment recommendations. Further study is warranted in practices with lower baseline rates of question-asking, prescription filling, and adherence to lifestyle recommendations. A longer intervention in which patients are exposed to the approach over several visits also is needed.

To read or post commentaries in response to this article, see it online at http://www.annfammed.org/cgi/content/full/8/2/151.

Key words: Health literacy; practice-based research; patient-clinician communications; patient education; multi-methods research; primary care

Submitted September 2, 2008; submitted, revised, June 30, 2009; accepted July 27, 2009.

Versions of this report were presented at the Annual Conference of the North American Primary Care Research Group (NAPCRG) in Tucson, Arizona, on October 16, 2006, and at the AAFP Scientific Assembly in San Francisco, California, on September 30, 2005. 
Funding support: Funding for this project was made possible by a research grant from Pfizer, Inc to the AAFP Foundation.

Acknowledgments: This research was funded by an unrestricted grant from Pfizer, Inc to the AAFP NRN via the AAFP Foundation. The funder played no role in the design or conduct of the study, or interpretation or analysis of the data. The study data are owned and controlled by the AAFP NRN. The authors acknowledge the collaboration of the medical practices, study physicians, and practice study coordinators who executed the research protocol at their locations. We thank the following clinicians for their contributions: Alber Abrahim, MD; Olga AriasField; Chandra Batra, MD; Allison Braud; John Bucek, MD; Donna Bush; Sharon Buskin, LPN; Cindy Carlson, RN; Penny Carter; Georgina ChanPerdomo, MD; Elizabeth Corona; Clint Curtis, MD; Nancy Deleon; Dan Doyle, MD; Andrew Eisenberg, MD; Emil Faris, MD; John Farmer, DO; Troy Fiesinger, MD; Patricia Glowa, MD; Tom Golemon, MD; Stephanie Hardy; Michael Hartsell, MD; Tanya Hauf, RN; Meg Hayes, MD; Cindy Hendrickson, RN; Amanda Hillebrand; Jackie Hodgson, RN; Debbie Johnson; Raj Kachoria, MD, PC; Nina Katovic; Lou Kazal, MD; Scott Knutson, MD; Donald Kollisch, MD; Charles Korte, MD; Kim Krohn, MD MPH; Carol Kuhle, DO; Stacey Langley; Joel Lazar, MD; John MacMaster, DO; Frances Mallet, RN, MSN; Evelyn Mazariegos; Elaine Meier; Connie Mitchell; Samantha Moore, LPN; Marion Mueller, RN; Eden Murad, MD; Denise Nichols, PharmD; Bernard O'Brien, PAC; Shirley Ocloo, MD; Alex Perdomo, MD; Heather Pierce, MD; Robert Pieroni, MD; Dorothy Pieroni; Marina Raikhel, MD; Michael Reis, MD; Eugene Reynolds, MD; Carol Rodgers, RN; Chris Seidler, RN; Yogesh Shah, MD; Amit Shah, MD; Lisa Soldat, MD; Elisabeth Spector, MD, MPH; James Stevermer, MD, MSPH; Linda Stewart, MD; Rick Sone, MD, MPH; Gregg Stoner, MD; Steven Stripe, MD; Feliks Syniak, PhD; Vilmary Vazquez, NCMA; Christy Ward, LPN; Chris White, MD; Marilyn Wissmiller, RN; Sonja Woods, MD; and Frances Wu, MD.

\section{References}

1. Barrier PA, Li JT, Jensen NM. Two words to improve physician-patient communication: what else? Mayo Clin Proc. 2003;78(2):211-214

2. Ong LM, de Haes JC, Hoos AM, Lammes FB. Doctor-patient communication: a review of the literature. Soc Sci Med. 1995;40(7):903-918.

3. Lee SJ, Back AL, Block SD, Stewart SK. Enhancing physicianpatient communication. Hematology Am Soc Hematol Educ Program. 2002:464-483.

4. Nielsen-Bohlman L, Panzer AM, Kindig DA, eds. Health Literacy: A Prescription to End Confusion. Washington, DC: National Academies Press; 2004:368.

5. Roter DL, Hall JA. Studies of doctor-patient interaction. Annu Rev Public Health. 1989:10:163-180.

6. Department of Health and Human Services. Healthy People 2010. 2nd ed (with Understanding and Improving Health and Objectives for Improving Health). Washington, DC: US Government Printing Office; 2000.

7. Davis TC, Dolan NC, Ferreira MR, et al. The role of inadequate health literacy skills in colorectal cancer screening. Cancer Invest. 2001;19(2):193-200.

8. Davis TC, Arnold C, Berkel HJ, Nandy I, Jackson RH, Glass J. Knowledge and attitude on screening mammography among low-literate, low-income women. Cancer. 1996;78(9):1912-1920.

9. Williams MV, Baker DW, Parker RM, Nurss JR. Relationship of functional health literacy to patients' knowledge of their chronic disease. A study of patients with hypertension and diabetes. Arch Intern Med. 1998;158(2):166-172.

10. Williams MV, Baker DW, Honig EG, Lee TM, Nowlan A. Inadequate literacy is a barrier to asthma knowledge and self-care. Chest. 1998;114(4):1008-1015.
11. Baker DW, Parker RM, Williams MV, et al. The health care experience of patients with low literacy. Arch Fam Med. 1996;5(6):329-334.

12. Paasche-Orlow MK, Taylor HA, Brancati FL. Readability standards for informed-consent forms as compared with actual readability. N Engl J Med. 2003;348(8):721-726.

13. Stewart MA. Effective physician-patient communication and health outcomes: a review. CMAJ. 1995;152(9):1423-1433.

14. Stewart M, Brown JB, Boon H, Galajda J, Meredith L, Sangster M. Evidence on patient-doctor communication. Cancer Prev Control. 1999;3(1):25-30.

15. The Headache Study Group of The University of Western Ontario. Predictors of outcome in headache patients presenting to family physicians-a one year prospective study. Headache. 1986;26(6):285-294

16. Kinmonth AL, Woodcock A, Griffin S, Spiegal N, Campbell MJ; The Diabetes Care From Diagnosis Research Team. Randomised controlled trial of patient centred care of diabetes in general practice: impact on current wellbeing and future disease risk. BMJ. 1998;317(7167):1202-1208

17. Kaplan SH, Greenfield S, Ware JE Jr. Assessing the effects of physician-patient interactions on the outcomes of chronic disease. Med Care. 1989;27(3 Suppl):S110-S127.

18. Schillinger D, Piette J, Grumbach K, et al. Closing the loop: physician communication with diabetic patients who have low health literacy. Arch Intern Med. 2003;163(1):83-90.

19. Woodwell DA, Cherry DK. National Ambulatory Medical Care Survey: 2002 summary. Adv Data. 2004;(346):1-44.

20. Tunis SR, Stryer DB, Clancy CM. Practical clinical trials: increasing the value of clinical research for decision making in clinical and health policy. JAMA. 2003;290(12):1624-1632.

21. Chew LD, Bradley KA, Boyko EJ. Brief questions to identify patients with inadequate health literacy. Fam Med. 2004;36(8):588-594.

22. Dickinson LM, Basu A. Multilevel modeling and practice-based research. Ann Fam Med. 2005;3(Suppl 1):S52-S60.

23. Littell RC, Milliken GA, Stroup WW, Wolfinger RD. SAS System for Mixed Models. Cary, NC: SAS Publishing; 1996:156.

24. Butow PN, Dunn SM, Tattersall MH, Jones QJ. Patient participation in the cancer consultation: evaluation of a question prompt sheet. Ann Oncol. 1994;5(3):199-204.

25. McCann S, Weinman J. Empowering the patient in the consultation: a pilot study. Patient Educ Couns. 1996;27(3):227-234

26. Tabak ER. Encouraging patient question-asking: a clinical trial. Patient Educ Couns. 1988;12(1):37-49.

27. Cegala DJ, Marinelli TM, Post DM. The effects of patient communication skills training on compliance. Arch Fam Med. 2000;9(1):57-64.

28. Lewis CC, Pantell RH, Sharp L. Increasing patient knowledge, satisfaction, and involvement: randomized trial of a communication intervention. Pediatrics. 1991;88(2):351-358.

29. Roter DL. Patient participation in the patient-provider interaction: the effects of patient question asking on the quality of interaction, satisfaction and compliance. Health Educ Monogr. 1977;5(4):281-315

30. Thompson SC, Nanni C, Schwankovsky L. Patient-oriented interventions to improve communication in a medical office visit. Health Psychol. 1990;9(4):390-404.

31. Greenfield S, Kaplan S, Ware JE Jr. Expanding patient involvement in care. Effects on patient outcomes. Ann Intern Med. 1985;102(4): 520-528.

32. Greenfield S, Kaplan SH, Ware JE Jr, Yano EM, Frank HJ. Patients participation in medical care: effects on blood sugar control and quality of life in diabetes. J Gen Intern Med. 1988;3(5):448-457.

33. Post DM, Cegala DJ, Miser WF. The other half of the whole: teaching patients to communicate with physicians. Fam Med. 2002;34(5) 344-352.

34. Stange KC, Zyzanski SJ, Jaén CR, et al. Illuminating the 'black box'. A description of 4454 patient visits to 138 family physicians. J Fam Pract. 1998;46(5):377-389. 